\title{
Ruthenium-catalyzed ortho alkenylation of aromatic nitriles with activated alkenes via $\mathrm{C}-\mathrm{H}$ bond activation $\dagger$
}

51, 10738

Received 15th April 2015,

Accepted 21st May 2015

DOI: $10.1039 / c 5 c c 03112 e$

www.rsc.org/chemcomm

\author{
Mallu Chenna Reddy and Masilamani Jeganmohan*
}

\begin{abstract}
The ruthenium-catalyzed ortho alkenylation of substituted aromatic and heteroaromatic nitriles with activated alkenes providing ortho alkenylated aromatic and heteroaromatic nitriles in a highly regio- and stereoselective manner is described.
\end{abstract}

Selective transformation of the $\mathrm{C}-\mathrm{H}$ bond of organic moieties into $\mathrm{C}-\mathrm{C}$ and $\mathrm{C}-$ heteroatom bond catalyzed by transition metal complexes via $\mathrm{C}-\mathrm{H}$ bond activation is one of the most versatile and well-acknowledged methods in organic synthesis. ${ }^{1}$ This transformation has gained tremendous attention in chemical and pharmaceutical industries, because it provides step- and atom-economical routes to synthesize useful organic molecules from the readily available starting materials. ${ }^{2}$ Particularly, a transition metal-catalyzed oxidative cross-coupling of heteroatom substituted aromatics with alkenes has proven to be a highly efficient route to synthesize disubstituted alkenes without having any prefunctionalized starting materials in a highly regio- and stereoselective manner. ${ }^{3}$ The selectivity of the $\mathrm{C}-\mathrm{H}$ bond of organic moieties can be controlled by using suitable directing groups. In most cases, the lone pair of electrons of nitrogen or oxygen atom of the directing groups coordinate with the metal complex through $\sigma$-coordination and activate the $\mathrm{C}-\mathrm{H}$ bond of organic moieties selectively (Fig. 1, eqn (1)). ${ }^{4,5}$ The search for new variants to activate the $\mathrm{C}-\mathrm{H}$ bond of aromatics is very important to expand the synthetic scope of the alkenylation reaction. Very recently, Cheng's group disclosed an alkene assisted alkenylation of aromatics with activated alkenes in the presence of a palladium catalyst via an unusual carbon-carbon $\pi$-bond coordination (Fig. 1, eqn (2)). ${ }^{6}$

Nitrile is a versatile functional group which can be efficiently used for various organic transformations. ${ }^{7}$ In addition, nitrile group containing organic molecules are used as pharmaceuticals, pesticides and dyes. ${ }^{8}$ The strong electron withdrawing nature and

Department of Chemistry, Indian Institute of Science Education and Research, Pune 411021, India. E-mail: mjeganmohan@iiserpune.ac.in

$\dagger$ Electronic supplementary information (ESI) available: Detailed experimental procedures and spectroscopic data. See DOI: $10.1039 / \mathrm{c} 5 \mathrm{cc} 03112 \mathrm{e}$

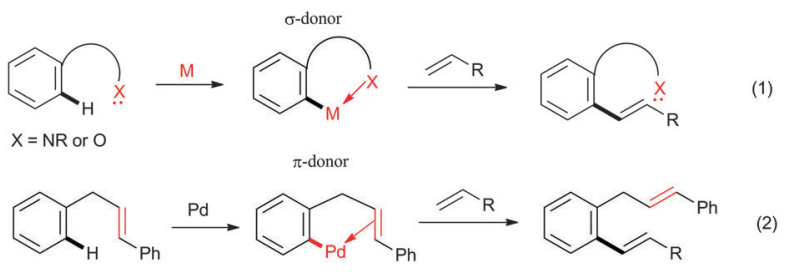

Fig. 1 Chelation-assisted $\mathrm{C}-\mathrm{H}$ bond alkenylation.

better hydrogen bond accepting properties of the nitrile group allow it to be used widely in designing drug molecules. Meanwhile, the cyano group can also be used as a directing group for the $\mathrm{C}-\mathrm{H}$ bond activation reactions. ${ }^{9-11}$ It is known that the lone pair of electrons of the nitrogen atom of the nitrile group of benzonitrile coordinate with the metal complex through $\sigma$-coordination, and this process leads to the formation of a linear metal complex. ${ }^{9}$ Also, a less likely, $\mathrm{C} \equiv \mathrm{N} \pi$-bond of benzonitrile coordinates with the metal, yielding the $\pi$-coordinated metal complexes. ${ }^{10}$ Recently, by employing the $\sigma$-coordination of the nitrile moiety, the meta $\mathrm{C}-\mathrm{H}$ bond of aromatics could be activated efficiently for the alkenylation reaction (Fig. 2, eqn (1)). ${ }^{11}$ To date, there is no report on the $\mathrm{C} \equiv \mathrm{N} \pi$-bond assisted alkenylation at the ortho position of aromatic nitriles with alkenes due to the difficulty in coordination of the $\pi$-bond of $\mathrm{C} \equiv \mathrm{N}$ with metals.

Our ongoing interest in the finding of a new $\mathrm{C}-\mathrm{H}$ bond transformation reaction prompted us to explore the possibility of $\mathrm{C} \equiv \mathrm{N} \pi$-bond assisted ortho alkenylation of substituted aromatic

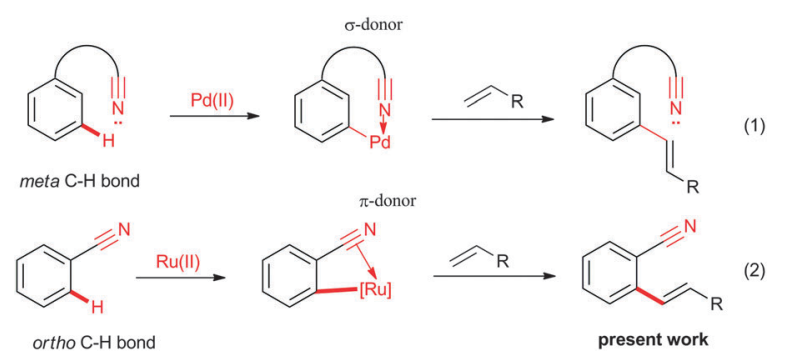

Fig. $2 \mathrm{C}-\mathrm{H}$ bond alkenylation of aromatic nitriles. 
nitriles with alkenes. Herein, we wish to report for the first time nitrile as a $\pi$-bond coordinating group for the ortho alkenylation of aromatic and heteroaromatic nitriles with activated alkenes in the presence of a ruthenium catalyst (Fig. 2, eqn (2)). The alkenylation reaction was compatible with functional group substituted aromatic nitriles. Later, the ortho alkenylated aromatic nitrile was converted into a chiral phthalide in the presence of AD-mix- $\beta$. By employing nitrile as a directing group, arylation was performed at the alkene $\mathrm{C}-\mathrm{H}$ bond of the ortho alkenylated aromatic nitriles with aromatic iodides in the presence of a Pd catalyst.

Initially, the ruthenium-catalyzed alkenylation reaction was examined using benzonitrile (1a) and $n$-butyl acrylate (2a) (Scheme 1). It is expected that the nitrogen atom of 1a prefers to coordinate with the metal via the lone pair electrons rather than $\pi$-coordination. However, for successful ortho $\mathrm{C}-\mathrm{H}$ bond activation, $\pi$-coordination of nitrile is crucial. Meanwhile, a metal acetate base is needed for the deprotonation of the $\mathrm{C}-\mathrm{H}$ bond of weak coordinating group substituted aromatics. Thus, a combination of the ruthenium catalyst and metal acetate having a Lewis acidic nature was selected. The main idea behind the selection of the Lewis acidic metal acetate is that the lone pair of nitrogen of the nitrile moiety would coordinate with the Lewis acid prior to the ruthenium catalyst reaction and block the corresponding site. Therefore, a possibility is created for the $\pi$-bond coordination of the nitrile moiety with the ruthenium catalyst and initiates the $\mathrm{C}-\mathrm{H}$ bond activation. With this idea, a combination of $\left[\left\{\operatorname{RuCl}_{2}(p \text {-cymene })\right\}_{2}\right](5 \mathrm{~mol} \%), \mathrm{AgSbF}_{6}(20 \mathrm{~mol} \%)$ and $\mathrm{Cu}(\mathrm{OAc})_{2} \cdot \mathrm{H}_{2} \mathrm{O}$ (2.0 equiv.) was used for the reaction. As a nitrile is a weak coordinating group, $\mathrm{AgSbF}_{6}$ was used to generate a cationic ruthenium species for the $\mathrm{C}-\mathrm{H}$ bond reaction. However, in the reaction, hydration takes place at the nitrile group and only benzamide (3a) was observed. If the same reaction is run for a long time, a cyclic isoindolin-1-one derivative was observed. ${ }^{12}$ Later, the reaction was examined using various Lewis acids such as $\mathrm{Co}(\mathrm{OAc})_{2}, \mathrm{Mn}(\mathrm{OAc})_{2}, \mathrm{Ag}_{2} \mathrm{O}, \mathrm{AgOAc}, \mathrm{Ag}_{2} \mathrm{CO}_{3}, \mathrm{Ag}\left(\mathrm{CF}_{3} \mathrm{CO}_{2}\right)$ and $\mathrm{Fe}(\mathrm{OAc})_{2}$ (2.0 equiv.). Very interestingly, in AgOAc, the ortho $\mathrm{C}-\mathrm{H}$ bond activation takes place selectively and further reaction with $n$-butyl acrylate (2a) provides the ortho alkenylated benzonitrile 4aa in $75 \%$ isolated yield. In the reaction, benzamide 3a was observed only in a very minor $3 \%$ yield. In other silver salts such as $\mathrm{Ag}_{2} \mathrm{O}, \mathrm{Ag}_{2} \mathrm{CO}_{3}$ and $\mathrm{Ag}\left(\mathrm{CF}_{3} \mathrm{CO}_{2}\right)$, the product 4 aa was observed in $45 \%, 49 \%$ and $61 \%$ yields. Benzamide $3 \mathbf{a}$ was observed in $25 \%, 19 \%$ and $14 \%$ yields, respectively. But, in $\mathrm{Co}(\mathrm{OAc})_{2}$ and $\mathrm{Mn}(\mathrm{OAc})_{2}$, benzamide $3 \mathrm{a}$ was observed in more than $45 \%$ and $51 \%$ yields and product 4 aa was observed in $15 \%$ and $19 \%$ yields, respectively. Meanwhile, the acidic solvent $\mathrm{AcOH}$ is crucial for the reaction. Other solvents such as 1,2-dichloroethane, THF,

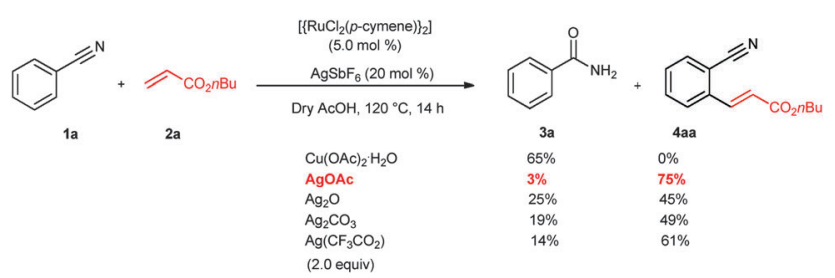

Scheme 1 ortho Alkenylation of benzonitrile. 1,4-dioxane, DMF, toluene and $\mathrm{CF}_{3} \mathrm{COOH}$ were not suitable for the reaction. However, in iso-PrOH, the product 4aa was observed only in $10 \%$ yield without benzamide $3 a$ formation.

The scope of the alkenylation reaction was examined with various activated alkenes 2 under the optimized reaction conditions (Table 1). Ethyl acrylate (2b), cyclohexyl acrylate (2c), phenyl acrylate (2d), benzyl acrylate (2e) and 2-phenoxyethyl acrylate (2f) reacted efficiently with 1a, providing the expected ortho alkenylated benzonitriles 4ab-af in 64\%, 79\%, 69\%, 67\% and 59\% yields, respectively (entries $1-5$ ). Further, $n$-butyl acrylate (2a), ethyl acrylate (2b), methyl acrylate (2g) and 2,2,2-trifluoroethyl acrylate (2h) also efficiently reacted with 2-naphthonitrile (1) yielding ortho alkenylated 2-naphthonitriles $\mathbf{4 b a - b h}$ in $75 \%$, $65 \%, 62 \%$ and $57 \%$ yields, respectively (entries 6-9). In the reaction, $\mathrm{C}-\mathrm{H}$ bond activation takes place selectively at the $\mathrm{C} 3$ position of 2-naphthonitrile (1b). Interestingly, phenyl vinyl sulphone (2i) was also efficiently involved in the reaction, providing product 4bi in $52 \%$ yield (entry 10 ).

The alkenylation reaction was compatible for a variety of sensitive functional groups such as $\mathrm{Br}, \mathrm{Cl}$, I, OMe, SMe and $\mathrm{CO}_{2} \mathrm{Me}$ substituted aromatic nitriles (Table 2). ortho Bromo (1c), chloro (1d) and methoxy (1e) substituted benzonitriles reacted efficiently with $n$-butyl acrylate (2a), providing the corresponding ortho alkenylated aromatic nitriles 4ca-ea in 51\%, 50\% and 47\% yields, respectively (entries 1-3). Subsequently, meta methylester (1f), iodo (19), bromo (1h), chloro (1i) and methoxy (1j) benzonitriles also efficiently participated in the reaction, providing the corresponding ortho alkenylated benzonitriles $\mathbf{4 f a}$-ja in 53\%, $48 \%, 45 \%, 44 \%$ and $42 \%$ yields, respectively, in a highly regioselective manner (entries 4-8). In all these reactions, $\mathrm{C}-\mathrm{H}$ bond activation takes place at a less hindered ortho $\mathrm{C} 6-\mathrm{H}$ bond of the

Table 1 Reaction of benzonitrile (1a) or 2-naphthonitrile (1) with activated alkenes $\mathbf{2} \mathbf{b}-\mathbf{i}^{a}$

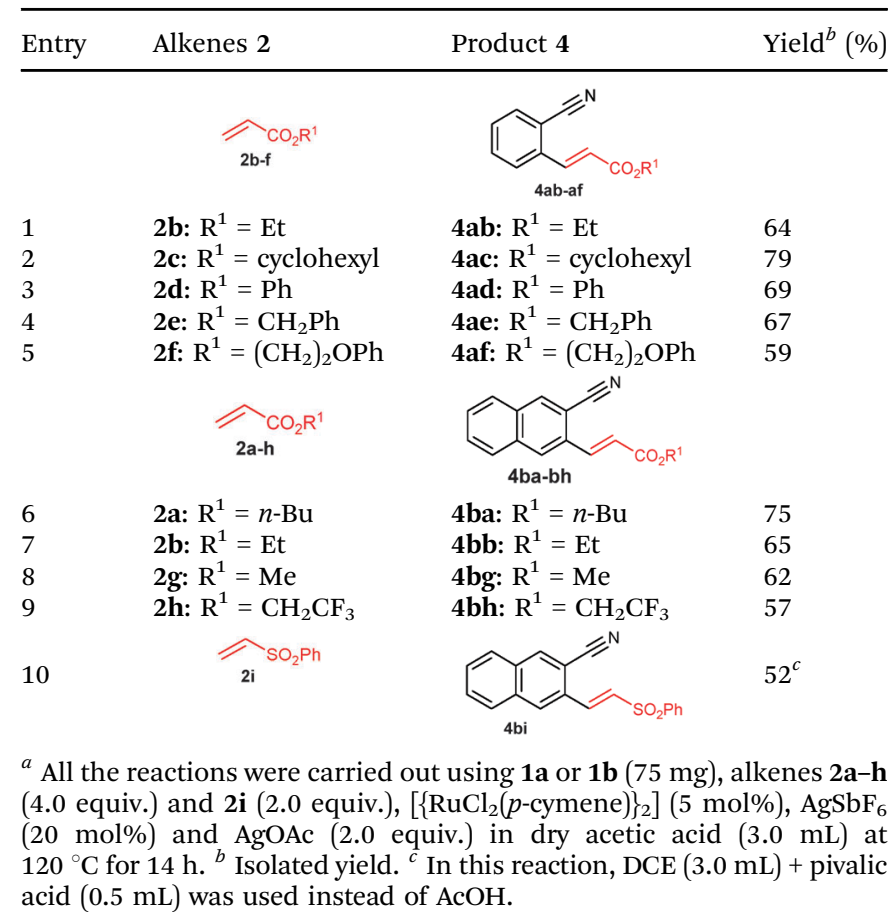


Table 2 Reaction of benzonitrile (1a) or 2-naphthonitrile (1) with activated alkenes $\mathbf{2} \mathbf{b}-\mathbf{i}^{a}$

Entry

${ }^{a}$ All the reactions were carried out using $1 \mathrm{c}-\mathbf{o}(75 \mathrm{mg})$, alkenes 2 (4.0 equiv.), $\left[\left\{\mathrm{RuCl}_{2}(p \text {-cymene })\right\}_{2}\right]$ (5 $\left.\mathrm{mol} \%\right), \mathrm{AgSbF}_{6}(20 \mathrm{~mol} \%)$ and AgOAc (2.0 equiv.) in dry acetic acid $(3.0 \mathrm{~mL})$ at $120{ }^{\circ} \mathrm{C}$ for $14 \mathrm{~h}$. ${ }^{b}$ Isolated yield. ${ }^{c}$ The reaction time was $16 \mathrm{~h}$.

benzonitriles (1f-j). 4-Methoxy (1/k) and 4-SMe (1) substituted benzonitriles provided the corresponding alkenylation products 4ka and $4 \mathbf{l a}$ in $42 \%$ and 57\% yields, respectively (entries 9 and 10). The alkenylation reaction was also examined with disubstituted benzonitriles (1m-o). 2,3-Dimethoxy (1m) and 3,4-dimethoxy (1n) benzonitriles reacted with $\mathbf{2 a}$ or $\mathbf{2 b}$, affording ortho alkenylated benzonitriles $4 \mathrm{ma}$ and $4 \mathrm{nb}$ in moderate $38 \%$ and $29 \%$ yields, respectively (entries 11 and 12). In the substrate 1n, the $\mathrm{C}-\mathrm{H}$ bond activation takes place at the less hindered ortho $\mathrm{C} 6-\mathrm{H}$ bond. In contrast, a sterically hindered ortho $\mathrm{C}-\mathrm{H}$ bond of piperonylonitrile (10) reacted with $2 \mathrm{a}$ or $2 \mathrm{~g}$ providing products 40 and $40 \mathrm{~g}$ in $52 \%$ and $48 \%$ yields, respectively (entries 13 and 14). The present result clearly reveals that a strong electron donating OMe group as the substituent on the benzonitrile decreases the yield of the product, and SMe, halogens and electron withdrawing substituents on the benzonitrile moderately increases the yield. In unsubstituted benzonitrile and 2-naphthonitrile substrates, good yields were observed.

The alkenylation reaction was also successfully extended with heteroaromatic nitriles (Scheme 2). Treatment of 2-nitrile

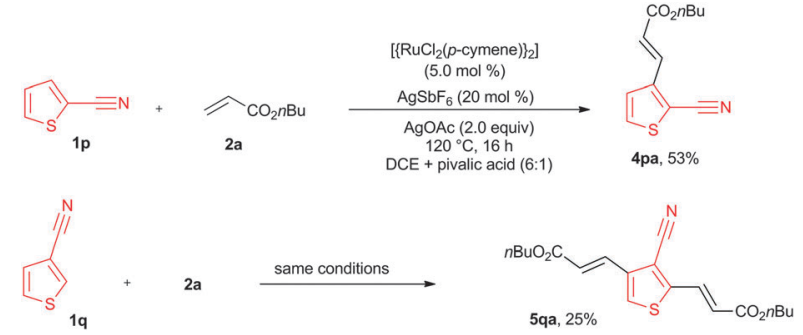

Scheme 2 Alkenylation of 2-cyano and 3-cyanothiophenes.

thiophene (1p) with $n$-butyl acrylate (2a) in the presence of $\left[\left\{\mathrm{RuCl}_{2}(p \text {-cymene })\right\}_{2}\right]$ (5 mol\%), $\mathrm{AgSbF}_{6}(20 \mathrm{~mol} \%)$ and AgOAc (2.0 equiv.) at $120{ }^{\circ} \mathrm{C}$ for $16 \mathrm{~h}$ provided 2-alkenyl-3-nitrile thiophene (4pa) in 53\% yield. 3-Nitrile thiophene (1q) reacted with $n$-butyl acrylate (2a) affording bis alkenylated 3-nitrile thiophene $5 q$ a in $25 \%$ yield. Next, the same reaction was examined using $\mathrm{Cu}(\mathrm{OAc})_{2} \cdot \mathrm{H}_{2} \mathrm{O}$ without AgOAc. Interestingly, in this reaction, bis alkenylated 3-nitrile thiophene 5qa was observed in $57 \%$ yield (Scheme 3). Similarly, $n$-ethyl acrylate (2b), cyclohexyl acrylate (2c), phenyl acrylate (2d), benzyl acrylate (2e), 2-phenoxyethyl acrylate (2f) and methyl acrylate (2g) also reacted with 1q, affording bis alkenylated 3-nitrile thiophenes 5qb-qg in 65\%, 48\%, 49\%, 47\%, $45 \%$ and $69 \%$ yields, respectively (Scheme 3).

A substituted ortho alkenyl aromatic nitrile is a versatile synthetic intermediate which can be used for synthesizing various useful organic molecules. ${ }^{7,8}$ ortho Alkenyl benzonitrile $4 \mathbf{a b}$ underwent an intramolecular cyclization in the presence of AD-mix- $\beta$, yielding a chiral phthalide 6 in 93\% yield in 99 ee\% (Scheme 4 ). ${ }^{13}$ By using AD-mix- $\alpha$, the reverse chiral phthalide derivative can be prepared in a highly enantioselective manner. ${ }^{13}$ Further,

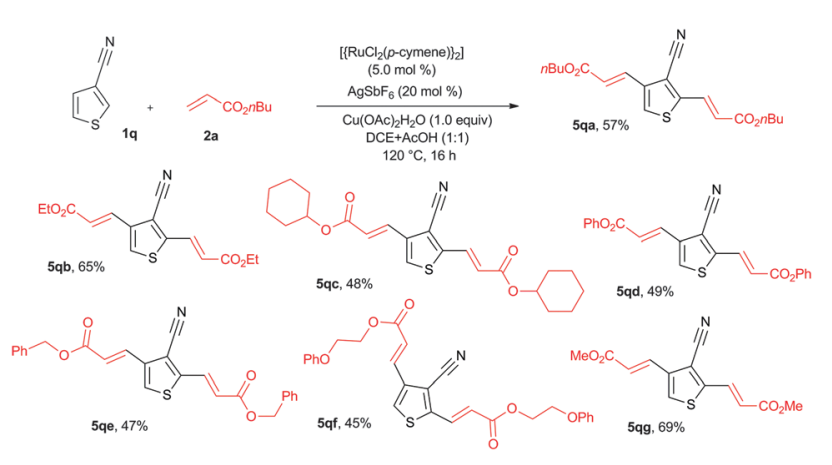

Scheme 3 bis Alkenylation of 3-cyanothiophene.

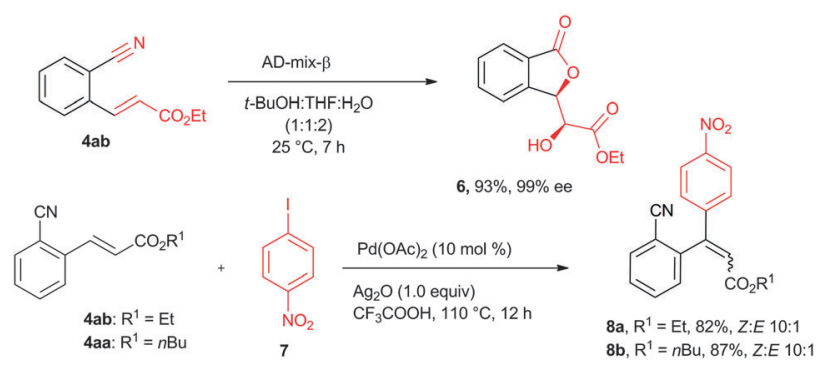

Scheme 4 Transformation of ortho alkenyl benzonitriles 4 . 


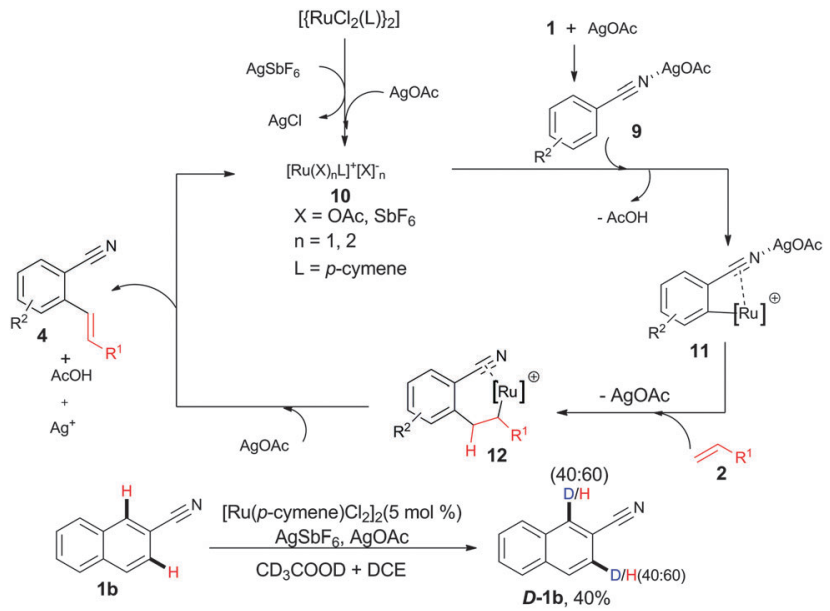

Scheme 5 Proposed mechanism.

by employing nitrile as a directing group, arylation was performed at the alkene $\mathrm{C}-\mathrm{H}$ bond of $\mathbf{4 a b}$ and $4 \mathbf{a a}$ with 4-iodo nitrobenzene (7) in the presence of $\mathrm{Pd}(\mathrm{OAc})_{2}$ and $\mathrm{Ag}_{2} \mathrm{O}$ in $\mathrm{CF}_{3} \mathrm{COOH}$ at $110{ }^{\circ} \mathrm{C}$ for $12 \mathrm{~h}$, giving trisubstituted alkenes $\mathbf{8 a}$ and $\mathbf{8 b}$ in $82 \%$ and $87 \%$ yields in a $10: 1 Z: E$ ratio.

A possible reaction mechanism is proposed to account for the present alkenylation reaction in Scheme 5. It is strongly believed that first the lone electron pair of the nitrogen atom of benzonitrile 1 coordinates with the Lewis acid AgOAc, providing a linear benzonitrile silver complex 9. A similar observation is strongly supported by DFT calculations. ${ }^{14}$ Subsequently, AgSbF 6 likely removes the $\mathrm{Cl}^{-}$ligand from the $\left[\left\{\mathrm{RuCl}_{2}(p \text {-cymene })\right\}_{2}\right]$ complex, providing a cationic ruthenium species 10. Coordination of the $\mathrm{C} \equiv \mathrm{N} \pi$-bond of $\mathbf{9}$ into the ruthenium species10 followed by ortho-metalation provides intermediate 11. Coordinative insertion of activated alkene $\mathbf{2}$ into the Ru-carbon bond of intermediate $\mathbf{1 1}$ affords intermediate 12. Subsequent $\beta$-hydride elimination of intermediate $\mathbf{1 2}$ in the presence of AgOAc gives product $\mathbf{4}$ and regenerates the active ruthenium species 10. To support the hypothesis that ortho $\mathrm{C}-\mathrm{H}$ bond cleavage of $\mathbf{9}$ is a reversible and rate determining process, the reaction of $\mathbf{1 b}$ was carried out in the presence of $\mathrm{CD}_{3} \mathrm{COOD}$ under similar reaction conditions. In this reaction, the product $\mathbf{D - 1} \mathbf{1}$ was observed in $40 \%$ yield, in which $40 \%$ of deuterium incorporation was observed at both C-1 as well as C-3 carbons of $\mathbf{1 b}$.

In conclusion, we have demonstrated a ruthenium-catalyzed $\mathrm{C} \equiv \mathrm{N} \pi$-bond assisted ortho alkenylation of substituted aromatic and heteroaromatic nitriles with activated alkenes providing ortho alkenylated aromatic and heteroaromatic nitriles in good to moderate yields in a highly regio- and stereoselective manner.

We thank the CSIR (02(0179)/14/EMR-II), India, for the support of this research. M.C.R. thanks the CSIR for a fellowship.

\section{Notes and references}

1 Selected references: (a) S. R. Neufeldt and M. S. Sanford, Acc. Chem. Res., 2012, 45, 936; (b) P. B. Arockiam, C. Bruneau and P. H. Dixneuf, Chem. Rev., 2012, 112, 5879; (c) K. M. Engle, T.-S. Mei, M. Wasa and J.-Q. Yu, Acc. Chem. Res., 2012, 45, 788; (d) L. Ackermann, Chem. Rev.,
2011, 111, 1315; (e) T. Satoh and M. Miura, Chem. - Eur. J., 2010, 16, 11212; $(f)$ G. Song, F. Wang and X. Li, Chem. Soc. Rev., 2012, 41, 3651.

2 Selected papers: (a) A. C. Grimsdale, K. L. Chan, R. E. Martin, P. G. Jokisz and A. B. Holmes, Chem. Rev., 2009, 109, 897; (b) A. Kraft, A. C. Grimsdale and A. B. Holmes, Angew. Chem., Int. Ed., 1998, 37, 402; (c) D. A. Colby, R. G. Bergman and J. A. Ellman, Chem. Rev., 2010, 110, 624 .

3 (a) J. L. Bras and J. Muzart, Chem. Rev., 2011, 111, 1170; (b) C. S. Yeung and V. M. Dong, Chem. Rev., 2011, 111, 1215; (c) L. Ackermann, Acc. Chem. Res., 2014, 47, 281.

4 (a) X. Huang, J. Huang, C. Du, X. Zhang, F. Song and J. You, Angew. Chem., Int. Ed., 2013, 52, 12970; (b) T. Ueyama, S. Mochida, T. Fukutani, K. Hirano, T. Satoh and M. Miura, Org. Lett., 2011, 13, 706; (c) K. Padala, S. Pimparkar, P. Madasamy and M. Jeganmohan, Chem. Commun., 2012, 48, 7140; (d) K. Padala and M. Jeganmohan, Org. Lett., 2011, 13, 6144; (e) K. Nobushige, K. Hirano, T. Satoh and M. Miura, Org. Lett., 2014, 16, 1188; $(f)$ D. Zhao, C. Nimphius, M. Lindale and F. Glorius, Org. Lett., 2013, 15, 4504; $(g)$ K. Padala and M. Jeganmohan, Org. Lett., 2012, 14, 1134; $(h)$ W. Ma, R. Mei, G. Tenti and L. Ackermann, Chem. - Eur. J., 2014, 20, 15248; (i) W. Ma and L. Ackermann, Chem. - Eur. J., 2013, 19, 13925; (j) M. C. Reddy and M. Jeganmohan, Eur. J. Org. Chem., 2013, 1150; (k) L. Ackermann, L. Wang, R. Wolfram and A. V. Lygin, Org. Lett., 2012, 14, 728; (l) G. Li, D. Leow, L. Wan and J.-Q. Yu, Angew. Chem., Int. Ed., 2013, 52, 1245.

5 (a) H.-L. Wang, R.-B. Hu, H. Zhang, A.-X. Zhou and S.-D. Yang, Org. Lett., 2013, 15, 5302; (b) K. Parthasarathy and C. Bolm, Chem. - Eur. J., 2014, 20, 4896; (c) Y. Yokoyama, Y. Unoh, K. Hirano, T. Satoh and M. Miura, J. Org. Chem., 2014, 79, 7649; (d) F. W. Patureau, T. Besset and F. Glorius, Angew. Chem., Int. Ed., 2011, 50, 1064; (e) K. M. Engle, D.-H. Wang and J.-Q. Yu, Angew. Chem., Int. Ed., 2010, 49, 6169; $(f)$ C. Wang, H. Chen, Z. Wang, J. Chen and Y. Huang, Angew. Chem., Int. Ed., 2012, 51, 7242; $(g)$ P. B. Arockiam, C. Fischmeister, C. Bruneau and P. H. Dixneuf, Green Chem., 2011, 13, 3075; (h) C. Wang and H. B. Ge, Chem. - Eur. J., 2011, 17, 14371; (i) B. Li, K. Devaraj, C. Darcel and P. H. Dixneuf, Green Chem., 2012, 14, 2706; $(j)$ K. S. Singh and P. H. Dixneuf, Organometallics, 2012, 31, 7320; (k) K. J. Stowers, K. C. Fortner and M. S. Sanford, J. Am. Chem. Soc., 2011, 133, 6541; (l) W. Dong, K. Parthasarathy, Y. Cheng, F. Pan and C. Bolm, Chem. - Eur. J., 2014, 20, 15732 .

6 (a) P. Gandeepan and C.-H. Cheng, Chem. - Asian J., 2015, 10, 824; (b) P. Gandeepan and C.-H. Cheng, J. Am. Chem. Soc., 2012, 134, 5738.

7 (a) Z. Rappoport, The Chemistry of the Cyano Group, Interscience Publishers, London, 1970; (b) R. C. Larock, Comprehensive OrganicTransformations: A Guide to Functional Group Preparations, VCH, NewYork, 1989; (c) P. Anbarasan, T. Schareina and M. Beller, Chem. Soc. Rev., 2011, 40, 5049.

8 (a) K. Friedrich and K. Wallenfels, in The Chemistry of the Cyano Group, ed. Z. Rappaport, Wiley, New York, 1970; (b) F. F. Fleming, L. Yao, P. C. Ravikumar, L. Funk and B. C. Shook, J. Med. Chem., 2010, 53, 7902.

9 (a) J. A. Davies and F. R. Hartley, Chem. Rev., 1981, 81, 79; (b) R. A. Michelin, M. Mozzon and R. Bertani, Coord. Chem. Rev., 1996, 147, 299; (c) M. F. Farona and N. J. Bremer, J. Am. Chem. Soc., 1966, 88, 3735.

10 (a) F. Kakiuchi, M. Sonoda, T. Tsujimoto, N. Chatani and S. Murai, Chem. Lett., 1999, 1083; (b) W. Li, Z. Xu, P. Sun, X. Jiang and M. Fang, Org. Lett., 2011, 13, 1286; (c) J.-C. Wan, J.-M. Huang, Y.-H. Jhan and J.-C. Hsieh, Org. Lett., 2013, 15, 2742; (d) W. Li and P. Sun, J. Org. Chem., 2012, 77, 8362; (e) B. Du, X. Jiang and P. Sun, J. Org. Chem., 2013, 78, 2786.

11 (a) H.-X. Dai, G. Li, X.-G. Zhang, A. F. Stepan and J.-Q. Yu, J. Am. Chem. Soc., 2013, 135, 7567; (b) R.-Y. Tang, G. Li and J.-Q. Yu, Nature, 2014, 507, 215; (c) M. Bera, A. Modak, T. Patra, A. Maji and D. Maiti, Org. Lett., 2014, 16, 5760.

12 M. C. Reddy and M. Jeganmohan, Org. Lett., 2014, 16, 4866.

13 R. S. Reddy, I. N. C. Kiran and A. Sudalai, Org. Biomol. Chem., 2012, 10, 3655.

14 T. Shoeib, H. E. Aribi, K. W. M. Siu and A. C. Hopkinson, J. Phys. Chem. A, 2001, 105, 710. 